\title{
The Impact of Metropolitan Structure on Commute Behavior in the Netherlands: A Multilevel Approach
}

\author{
TIM SCHWANEN, FRANS M. DIELEMAN, AND MARTIN DIJST
}

\begin{abstract}
This paper documents the investigation of the impact of metropolitan structure on the commute behavior of urban residents in the Netherlands. Not only has the impact of monocentrism versus polycentrism been analyzed, but the influence of metropolitan density and size has also been considered, together with the ratio of employment to population and the growth of the population and employment. Furthermore, data are used at a variety of levels of analysis ranging from the individual worker to the metropolitan region rather than being drawn from aggregate level statistics alone. Multilevel regression modeling is applied to take account of the interdependencies among these levels of aggregation. With regard to mode choice, the results indicate that the probability of driving an auto to work is lower in employment-rich metropolitan regions, and rises as the number of jobs per resident has grown strongly. Furthermore, women in most polycentric regions are less likely to commute as an auto driver. All else being equal, commute distances and times for auto drivers are longer in most polycentric regions than in monocentric urban areas. In addition, commute time as an auto driver rises with metropolitan size, whereas commute distance depends on employment density and the growth of the number of jobs per resident. The investigation shows that metropolitan structure, although significantly influencing commute patterns, explains only a small part of the variation of individuals' commute behavior.
\end{abstract}

\section{Introduction}

T he role of the private automobile in shaping current metropolitan settlement patterns is well recognized. Along with rising affluence and structural economic changes such as de-industrialization, the increase in auto ownership after World War II was one of the major forces in the deconcentration of land use (Anas, Arnott, and Small 1998). In both

Tim Schwanen is a post-doctoral researcher at the Urban Regional Research Center, Utrecht (URU) and a faculty member in the Department of Geosciences at Utrecht University, Utrecht, The Netherlands. His email address is T.Schwanen@geog.uu.nl. Frans M. Dieleman, professor in urban geography, and Martin Dijst, associate professor in urban geography, are also faculty members in the Department of Geociences at Utrecht University. This research was enabled by grant 425-13-003 of the Netherlands National Science Foundation (NWO) to the Urban Research Center, Utrecht (URU). The insightful comments of the two anonymous reviewers and the guest editors are gratefully acknowledged.

Submitted Sept. 2003.

(C) 2004 Gatton College of Business and Economics, University of Kentucky. Published by Blackwell Publishing, 350 Main Street, Malden MA 02148 US and 9600 Garsington Road, Oxford OX4, 2DQ, UK. 
the U.S. and Western Europe, metropolitan settlement patterns have changed from monocentric - a situation with a concentration of most functions in the urban core with residences clustered around this core in declining densities - to polycentric. In such regions urban functions have decentralized from the core area across urban space, and many have relocated to suburban nodes of development or edge cities (Forstall and Greene 1997).

Notwithstanding this acknowledgment, the literature on the impact of polycentrism on commuting by private automobile is not unequivocal. Consider mode choice, for example. Many studies found that a development toward polycentrism was accompanied by a decline in the importance of mass transit and cycling and walking (Schwanen, Dieleman, and Dijist 2001). This is hardly surprising, since the rise of polycentrism has come about through increased auto ownership. Nevertheless, some empirical investigations suggest that polycentrism need not by definition result in greater automobile dependence (Bolotte 1991, for example). In addition, the evidence about the effect of polycentrism on mode choice is rather fragmentary; few systematic analyses have been carried out that rigorously compare mode choice across metropolitan regions. With regard to commute time, some U.S. researchers have found that automobile commute times tend to be lower in polycentric than in monocentric metropolitan regions (Gordon, Richardson, and Jun 1991, for example). Again, this makes sense, because the rise of polycentric urban areas is at least in part the result of the preference of households and firms for less congested locations. Others have, however, questioned this (Cervero and $\mathrm{Wu} 1998$, for example).

Although previous work has made a substantial contribution to current understanding of variation in commute patterns across metropolitan regions, several gaps in the existing literature can be identified. For example, most investigations of commute time or distance draw on U.S. data; evidence from European contexts is scarcer. In addition, researchers have predominantly attributed variations in commute patterns to changes or differences in the spatial distribution of employment relative to residence: that is, whether a metropolitan region has a monocentric or polycentric character. Despite their potential importance to commuting, other factors that may differ among metropolitan regions, such as differences in prosperity and employment growth, have often not been taken into account. Moreover, many previous papers have relied on aggregate level statistics and do not account for microlevel variation in commute behavior.

This paper reports the comparison of the commute patterns of workers in twenty-six urban areas in the Netherlands. Using data from the 1998 Netherlands National Travel Survey, the research seeks to explain differences in commute behavior across metropolitan regions by linking them not only to a classification of monocentric and polycentric structures, but also to a range of other characteristics of the metropolitan regions. These characteristics include the number of jobs per hectare or per inhabitant and the development in the number of jobs during the economic boom period in the Netherlands in the second half of the 1990s. In this sense, this paper extends the authors' earlier work concentrating on the impact of the monocentric or polycentric character of urban areas on automobile use (Schwanen, Dieleman, and Dijist 2001, 2003). In addition, travel data and explanatory variables are utilized at more than one level of aggregation. Instead of using 
metropolitan-wide statistics alone, data at the level of the individual worker, the household, and the residential zone within the metropolitan region have also been incorporated. Multilevel regression modeling has been applied to account for the fact that explanatory variables are measured at four levels of aggregation.

The remainder of the paper starts with a brief discussion of the literature on the impact of polycentrism and other aspects of metropolitan structure on commute behavior. In section three the data and research methods used for the empirical analysis are described. The results for the analysis of mode choice are presented in section four, and those pertaining to commute distance and time in section five. The paper concludes with a discussion.

\section{Study Background}

In the literature on the impact of metropolitan structure on commuting, the co-location hypothesis originally formulated by Gordon and colleagues takes a central position (Gordon and Wong 1985; Gordon, Kumar, and Richardson 1989a, 1989b, and Gordan, Richardson, and Jun 1991). They argue that individual households seek ways to avoid the time penalties caused by the extensive congestion in monocentric urban areas by periodically changing their workplace or residence. This residential and job mobility allows them to travel shorter distances and/or to make use of less congested routes. Firms also attempt to escape the disadvantages of high-density locations - traffic congestion, poor accessibility to the suburban labor force, high land prices, and limited opportunities for spatial extension - and find new locations in less congested parts of the metropolitan region. In aggregate, the result is a dispersal of activities across urban space and the rise of polycentric urban areas with lower average commute times. Thus, when workers are assumed to minimize travel time, commute times can be expected to tend to be lower in polycentric than in monocentric areas. The same may be the case for commute distance. ${ }^{1}$ A series of empirical studies has been published that supports these notions, for example Gordon et al. (1989a, 1989b, and 1991) and Levinson and Kumar (1994). Schwanen, Dieleman, and Dijist (2001, 2002, and 2003) provide a detailed review of this literature.

Nevertheless, other empirical studies have drawn opposite conclusions. Cervero and $\mathrm{Wu}$ (1998), for instance, indicated that in the San Francisco Bay Area both commute times and distances rose after an increase in the degree of polycentrism. Several phenomena may account for the longer commute times and distances in polycentric regions. Constraints on residential choice behavior may prevent a minimization of commute time or distance. There may be several workers in a household (Clark, Huang, and Withers 2002; Giulano and Small 1993), or a lag in housing development near suburban employment concentrations (Cervero and Wu 1997), or zoning measures creating greenbelts around urban nodes (Jun and Bae 2000). Furthermore, the mechanisms underlying the co-location may not be valid for all people at all times. Salomon and Mokhtarian (1997) point out that employment or residential relocation may serve as a means for households to escape congestion, but it often functions as a last resort when other strategies have proven inadequate. The reason for this reluctance to relocate is that substantial costs are involved in changing jobs 
and particularly the place of residence, not only for the worker but also his/her family. In addition, the assumption of travel minimization may be challenged; for commuters, traveling may have an intrinsic value of its own and may even be perceived as a positive rather than negative expenditure of time (Mokhtarian and Salomon 2001).

A transition from monocentrism to polycentrism may also affect mode choice. A shift from transit use to solo driving has been observed in many spatial contexts (Schwanen, Dieleman, and Dijist 2001). The spatially diffuse commute patterns that characterize polycentric urban areas make it more difficult for transit providers to compete with the ubiquity of the private automobile. The advocates of strong planning interference argue that only massive investments in public transportation networks or the channeling of decentralizing land uses along public transport infrastructure are capable of offsetting the impact of decentralization (Newman and Kenworthy 2000). Bolotte (1991) provides some empirical support for this point of view. He showed that, in the Paris region, the share of public transit in the mode split remained at a stable level of 31 percent in the period 1971-1989. In addition, Schwanen et al. (2001) found relatively high public transport use and walking and cycling in some types of polycentric regions in the Netherlands, whereas the opposite was the case for other sorts of polycentric regions. Thus, polycentrism may not always be associated with greater probabilities of driving an automobile to work.

This short review of previous empirical studies serves to illustrate that the effects of metropolitan structure on commute behavior are not undisputed. Drawing conclusions about the impact of metropolitan structure on the basis of previous empirical work is not without problems, for at least two reasons: The role of many potentially important explanatory factors at the metropolitan level other than monocentrism and polycentrism has often been neglected; and the application of different research methods makes comparison of the results from various studies difficult.

Researchers have mostly been concerned with relating differences in metropolitan commute patterns across time and space to changes or variation in the distribution of employment relative to that of the population. Thus, much of the earlier work (including the authors' own) has limited the influence of metropolitan structure on commuting to the impact of monocentrism and polycentrism; the role of other dimensions of metropolitan spatial structure has sometimes been downplayed, or even ignored. This neglect seems a little surprising given that, among other things, the literature on excess commuting ${ }^{2}$ has long claimed that observed commute behavior cannot be explained by the distribution of housing and jobs alone (Giuliano and Small 1993; Scott, Kanaroglou, and Anderson 1997). Of course, there are some exceptions. Gordon, Kumar, and Richardson (1989a), for example, analyze the impact of factors such as metropolitan size and density on commute times in addition to the effect of the degree of polycentrism. However, their analysis is limited to commute time and does not consider commute distance or mode choice.

Having asserted that the difference between monocentrism and polycentrism is not the only relevant factor affecting commute behavior, a brief discussion of other differences among metropolitan regions that require consideration is now in order. Metropolitan-wide population and employment densities provide a potentially important dimension of met- 
ropolitan structure. Higher densities could be expected to be associated with lower automobile use and shorter commute distances (Newman and Kenworthy 2000). Because higher densities also lead to higher levels of congestion, the effect on commute time is questionable (Levinson and Kumar 1997). The size of a metropolitan area is also relevant. Although some U.S. researchers have found little or no effect of metropolitan size on commute distance or time (Gordon, Kumar, and Richardson 1989b; Levinson and Kumar 1997), there is some evidence that, in Europe, average commute distance or time rises as urban areas become larger (Coombes and Raybould 2001; Schwanen 2002). This appears reasonable, because the maximum commute distance or time can become longer as the size of urban areas is larger.

Some factors that are less directly related to the spatial location of employment and population are also worthy of consideration: for example, the ratio of total employment in an urban area to the labor force in that urban area. In the Netherlands there is considerable variation in this ratio. In Amsterdam the number of jobs relative to the resident labor force is relatively high, while in Nijmegen it is relatively low (Louter, van Koppenhagen, and Eding 2001). If the number of jobs in the urban area is relatively low, workers living in that region may find it harder to find a suitable job near their residential location (Levinson 1998). In aggregate, this low job ratio may result in a larger average commute distance and time and, related to this, lower shares of cycling and walking - modes that are important in Dutch cities - in the mode split for commuting (Schwanen, Dieleman, and Dijist 2001). This reasoning is similar to that underlying the idea of jobs-housing balance in the U.S. literature (Cervero 1989). However, there is one important differencespatial scale. Ratios of jobs to residents or dwellings are normally measured for zones within urban areas, but they are used here to discriminate between urban areas. The reason for this is that, given the fact that in the Netherlands urban areas are geographically small units, commuting between them is feasible. Daily urban systems do not function as closed systems without cross-border commute traffic.

Cross-sectional comparisons of metropolitan commute patterns might also attempt to incorporate certain dynamics over time in the number of workers and employment in urban areas. Of course, the relative locations of employment and population in an urban area at a single point in time are the spatial outcomes of such developments. In the short term, however, time lags may occur between residential and employment locations, in particular when economic growth is strong and residential neighborhoods are not immediately developed close to new concentrations of employment. This mismatch may create longer commute times or distances. During the 1990s, such a situation may have developed in some urban regions in the Netherlands. The economy was booming and net incomes rose for all segments of the population. There was particularly strong growth in the "new" economic sectors, such as in business and financial services and in information and communication technologies. Many (but by no means all) firms belonging to these sectors have a preference for locations on the urban fringe, or along highways that are readily accessible by private automobile (Atzema 2001). As a result, a further decentralization of employment has taken place. Since these economic sectors are relatively overrepresented in 
regions located in the northern part of the Randstad Holland in cities such as Amsterdam, Utrecht, and Amersfoort (Lambooy 1998), it could be expected that the impact of employment growth on commute behavior will be relatively large in these regions.

A second difficulty in comparing the results of empirical studies of metropolitan commuting patterns is that different research methodologies have been applied. Many researchers have relied on aggregate data for comparing commute patterns, taking some spatial unit as the unit of analysis. However, disaggregate data at the individual worker level should preferably be used, because considerable variation exists between individuals in the resources available for, and constraints affecting, commuting. Hence, factors relating to a worker's role within the household and socioeconomic position, including auto availability, should be taken into account. ${ }^{3}$ Moreover, when analyzing the role of the variables at the metropolitan level, attention should preferably also be paid to locational characteristics at lower geographical levels. Many studies have addressed the reasons for intra-urban variations in commute behavior and have shown that, apart from the individual characteristics of the commuter, local residential density and distance to the CBD or suburban employment centers are important variables capable of explaining differences in commuting patterns within metropolitan areas (Levinson 1998; Levinson and Kumar 1997; Shen 2000; Wang 2000). Thus, to take into account the fact that the influence of the urban context on commuting is not restricted to a single geographical level, variables at multiple geographical scales have to be linked to commute patterns. In this paper commute behavior has been conceptualized as being influenced by the characteristics of workers, their households, their residential environment, and various characteristics of the metropolitan region in which they live and work (Table 1). Multilevel regression techniques are employed to deal with the interdependencies and violations of the assumptions underlying conventional regression modeling that this conceptualization creates. This type of analysis has only recently been introduced to the analysis of commute patterns (e.g., Bhat 2000; Snellen, Borgers, and Timmermans 2002; Schwanen and Dijst 2002).

\section{Research Design}

Data. The 1998 Netherlands National Travel Survey (NTS) has been used for the empirical analysis. Initiated in 1978, this survey is a continuous inquiry into the travel behavior of Dutch households. Every year, approximately 70,000 households are asked to participate in the survey. It yields data on the travel behavior of some 130,000 individuals including children over the age of four. Respondents are asked to provide information on personal and household attributes and to complete a trip diary for a single day. For each trip undertaken, respondents have to report the purpose, the mode chosen, the distance traveled, the start and end times, and the origin and destination (Statistics Netherlands 1999).

Heads of households and their partners (if present) residing in one of the twenty-six metropolitan regions and making at least one commute trip on the day of inquiry were selected for the empirical analysis reported here. Only individuals whose out-of-home activity pattern starts and ends at the home location have been included in the analysis. 
Furthermore, for all commute trips in the activity pattern, the main travel mode and the distance covered had to be known. In total, data for 14,590 workers was used in the empirical analysis. Three commute variables were constructed on the basis of the information respondents reported. For all 14,590 workers, a binary commute mode choice variable was

TABLE 1. EXPLANATORY VARIABLES.

\begin{tabular}{|c|c|c|c|c|}
\hline $\begin{array}{l}\text { Level of } \\
\text { analysis }\end{array}$ & Variable name & Description & Mean $^{1}$ & S.D. \\
\hline \multirow[t]{8}{*}{ Worker } & $\begin{array}{l}\text { Auto } \\
\text { availability } \\
\text { index }\end{array}$ & $\begin{array}{l}\text { Ratio of the number of autos } \\
\text { to the number of household } \\
\text { members with a valid } \\
\text { driver's license; set to } \\
\text { zero if person has no } \\
\text { driver's license }\end{array}$ & 0.640 & 0.386 \\
\hline & $\begin{array}{l}\text { Personal } \\
\text { income }\end{array}$ & $\begin{array}{l}\text { A worker's annual net income } \\
\left({ }^{*} 10,000 \text { gld. }\right)\end{array}$ & 42.8 & 18.2 \\
\hline & Education & Low & $28.1 \%$ & \\
\hline & & Medium & $34.4 \%$ & \\
\hline & & High & $37.5 \%$ & \\
\hline & Age & In years & 40.8 & 10.3 \\
\hline & Gender & Male & $61.2 \%$ & \\
\hline & & Female & $38.8 \%$ & \\
\hline \multirow[t]{7}{*}{ Household } & Household type & Single worker & $13.2 \%$ & \\
\hline & & Two-worker couple & $24.1 \%$ & \\
\hline & & One-worker couple & $7.8 \%$ & \\
\hline & & $\begin{array}{l}\text { Two-worker family } \\
\text { (youngest child <12 yr.) }\end{array}$ & $17.4 \%$ & \\
\hline & & $\begin{array}{l}\text { One-worker family } \\
\text { (youngest child <12 yr.) }\end{array}$ & $12.0 \%$ & \\
\hline & & $\begin{array}{l}\text { Single-parent family } \\
\quad \text { (youngest child }<12 \text { yr.); }\end{array}$ & $0.7 \%$ & \\
\hline & & Other household & $24.7 \%$ & \\
\hline \multirow[t]{5}{*}{$\begin{array}{l}\text { Residential } \\
\text { municipality }\end{array}$} & $\begin{array}{l}\text { Population } \\
\text { density }\end{array}$ & $\begin{array}{l}\text { Number of residents } \\
\text { per square } \mathrm{km}\end{array}$ & $2,080.8$ & $1,523.8$ \\
\hline & $\begin{array}{l}\text { Residential } \\
\text { density }\end{array}$ & $\begin{array}{l}\text { Number of residences } \\
\text { per square } \mathrm{km}\end{array}$ & 915.2 & 725.1 \\
\hline & $\begin{array}{l}\text { Employment } \\
\text { density }\end{array}$ & Number of jobs per square km & 964.9 & 806.4 \\
\hline & $\begin{array}{l}\text { Area } \\
\text { municipality }\end{array}$ & Size of municipality in $\mathrm{km}^{2}$ & $6,954.1$ & $6,234.8$ \\
\hline & Core city & $\begin{array}{l}\text { Main settlement within } \\
\text { metropolitan region }\end{array}$ & $46.3 \%$ & \\
\hline
\end{tabular}


A MULTILEVEL APPROACH 311

TABle 1. (CONTINUED)

\begin{tabular}{|c|c|c|c|c|}
\hline $\begin{array}{l}\text { Level of } \\
\text { analysis }\end{array}$ & Variable name & Description & Mean $^{1}$ & S.D. \\
\hline & Growth center & $\begin{array}{l}\text { Settlement designed to } \\
\text { accommodate population } \\
\text { and employment relocating } \\
\text { from the core cities; } \\
\text { centerpiece of Netherlands } \\
\text { national spatial planning } \\
\text { policy in the 1970s } \\
\text { and 1980s }\end{array}$ & $10.1 \%$ & \\
\hline \multirow{13}{*}{$\begin{array}{l}\text { Metropolitan } \\
\quad \text { region (DUS) }\end{array}$} & DUS type & Centralized & $36.8 \%$ & \\
\hline & & Decentralized & $40.7 \%$ & \\
\hline & & Self-contained & $9.1 \%$ & \\
\hline & & Exchange-commuting & $13.4 \%$ & \\
\hline & Area DUS & Size of DUS in $\mathrm{km}^{2}$ & $66,049.5$ & $63,843.9$ \\
\hline & $\begin{array}{l}\text { Number of } \\
\text { residents }\end{array}$ & In 1,000 residents & 536.8 & 411.7 \\
\hline & Number of jobs & In 1,000 jobs & 255.0 & 212.1 \\
\hline & $\begin{array}{l}\text { Population } \\
\text { density }\end{array}$ & $\begin{array}{c}\text { Number of residents } \\
\text { per square } \mathrm{km}\end{array}$ & $1,024.6$ & 473.4 \\
\hline & $\begin{array}{l}\text { Employment } \\
\text { density }\end{array}$ & $\begin{array}{l}\text { Number of jobs per } \\
\text { square km }\end{array}$ & 460.7 & 194.7 \\
\hline & $\begin{array}{l}\text { Ratio of jobs to } \\
\text { residents }\end{array}$ & $\begin{array}{l}\text { Number of jobs per } \\
\text { square } \mathrm{km}\end{array}$ & 0.458 & 0.070 \\
\hline & $\begin{array}{l}\text { Growth of } \\
\text { number } \\
\text { of residents }\end{array}$ & $\begin{array}{l}\text { Average annual growth } \\
\text { (in \%) of the number of } \\
\text { residents in a DUS in } \\
\text { the period 1994-1999 }\end{array}$ & 0.354 & 0.274 \\
\hline & $\begin{array}{c}\text { Growth of } \\
\text { number } \\
\text { of jobs }\end{array}$ & $\begin{array}{l}\text { Average annual growth } \\
\text { (in \%) of the number of } \\
\text { jobs in a DUS in the } \\
\text { period 1994-1999 }\end{array}$ & 2.519 & 0.832 \\
\hline & $\begin{array}{l}\text { Growth of ratio } \\
\text { of jobs to } \\
\text { residents }\end{array}$ & $\begin{array}{l}\text { Average annual growth } \\
\text { (in \%) of the number of } \\
\text { jobs per resident in a } \\
\text { DUS in the period } \\
1994-1999\end{array}$ & 2.154 & 0.688 \\
\hline
\end{tabular}

${ }^{1} \mathrm{~N}=14,590$ individuals. 
created distinguishing between those who used the auto driver mode to commute and those who commuted by any other means of transport. Of all workers considered 7,996 commuters (54.8 percent) drive an automobile to work. The self-reported distance these automobile drivers traveled and time they spent for all their commute trips were totaled and the variables total daily commute distance as an auto driver and time spent as an auto driver were created. The reasons for restricting the analysis of commute distance and commute time to automobile drivers are twofold. First, the focus of much of the literature, particularly in U.S. studies, is automobile travel. Second, a control is needed for the confounding effects of mode choice. This could have been done by introducing commute mode as an explanatory variable in a model explaining commute mode and distance for all travelers. However, given that mode choice and travel time are jointly determined, this would introduce endogeneity basis in the results. Therefore, limiting the analysis to auto drivers is preferred.

The NTS provides information on a range of personal and household attributes, which was used to create a set of variables at the individual worker and household level for the empirical analysis (Table 1). A variable indicating the municipality of residence was also available; it has been used as a proxy for the residential zone. Based in part on the STATLINE database of Statistics Netherlands, the following context data at this level of analysis were created: three density measures, a zonal size indicator, and dummy variables for core cities and growth centers. The core city variable indicates the central part of each metropolitan region where the largest employment concentration is located; it serves as a proxy indicator for the distance between a residential area and the main employment center in a metropolitan region. Growth centers were the centerpiece of Netherlands national spatial planning in the 1970 s and early 1980 s. In an attempt to influence the massive suburbanization after the increase in automobile ownership in the 1960s and 1970s, the national government designated a number of settlements with the intention of curbing the sprawling households and firms. These new towns were intended to become self-contained, but they instead turned into dormitory towns. Eventually, they attracted substantial employment, although the (qualitative) mismatch between residence and employment has remained. Many people working in the growth centers commute from elsewhere, whereas those residing in the new towns tend to work in other employment centers (Van der Laan 1998).

The data at the level of the metropolitan region or Daily Urban System (DUS) were derived from Van der Laan (1998) and Louter, Van Koppenhagen, and Eding (2001). The latter source provided the input for a range of potentially explanatory variables: metropolitan size and density indicators, together with the number of jobs per resident, and three measures of employment and population growth (Table 1). In addition, while many researchers have acknowledged that monocentrism and polycentrism are the extremes of a continuum, they do not generally pay explicit attention to distinct differences among polycentric regions (Schwanen, Dieleman, and Dijist 2003). The categorization of DUSs developed by Van der Laan (1998) does incorporate variation in polycentric forms and has therefore been used for the current study. Four types of DUSs have been defined (Figure 1): 


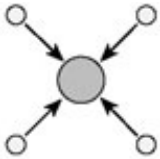

centralized

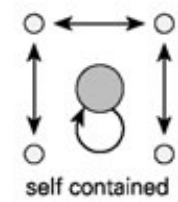

core city

suburb

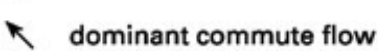

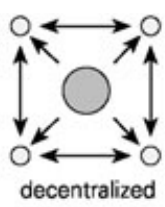

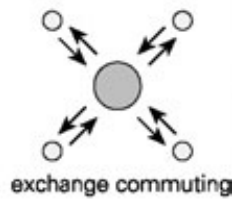

\section{要}

Figure 1. Schematic Representation of Types of DUS.

Centralized: this type of DUS resembles the traditional, monocentric urban region. Home-to-work commutes are mainly oriented toward the core city.

Decentralized: a very large share of employment is located in suburban areas; many central-city residents commute to the suburbs each morning while many suburbanites commute to work located in other suburbs.

Self-contained: many suburban residents work in the suburbs and many central-city workers are locally employed. This type of urban region consists of relatively independent, substitutable, and self-contained nodes. This archetypal polycentric region develops when workers minimize travel expenditure (Schwanen, Dieleman, and Dijist 2003).

Exchange-commuting: here, there are reciprocal relationships between the suburbs and the core area with many suburbanites working in the central city and many urbanites traveling to work in the suburbs. The level of self-containment is low; employment centers are complementary to each other rather than substitutable (Schwanen et al. 2003).

The spatial distribution of these types of DUSs over the Netherlands shows a clear pattern (Figure 2). Decentralized regions are mainly located in the western part of the country - the Randstad Holland - whereas centralized systems tend to be concentrated in the north, east, and south. This distribution can be explained by reference to the differences in regional economic structure (Van der Laan 1998). While services dominate the economic structure over the whole country, in the north, east, and south, agricultural and traditional industrial employment, such as food processing (North and East) and heavy and (petro) chemical industry (the regions of Enschede, Arnhem, and Geleen-Sittard, for example) are still more important than in the west. As a consequence, more traditional 


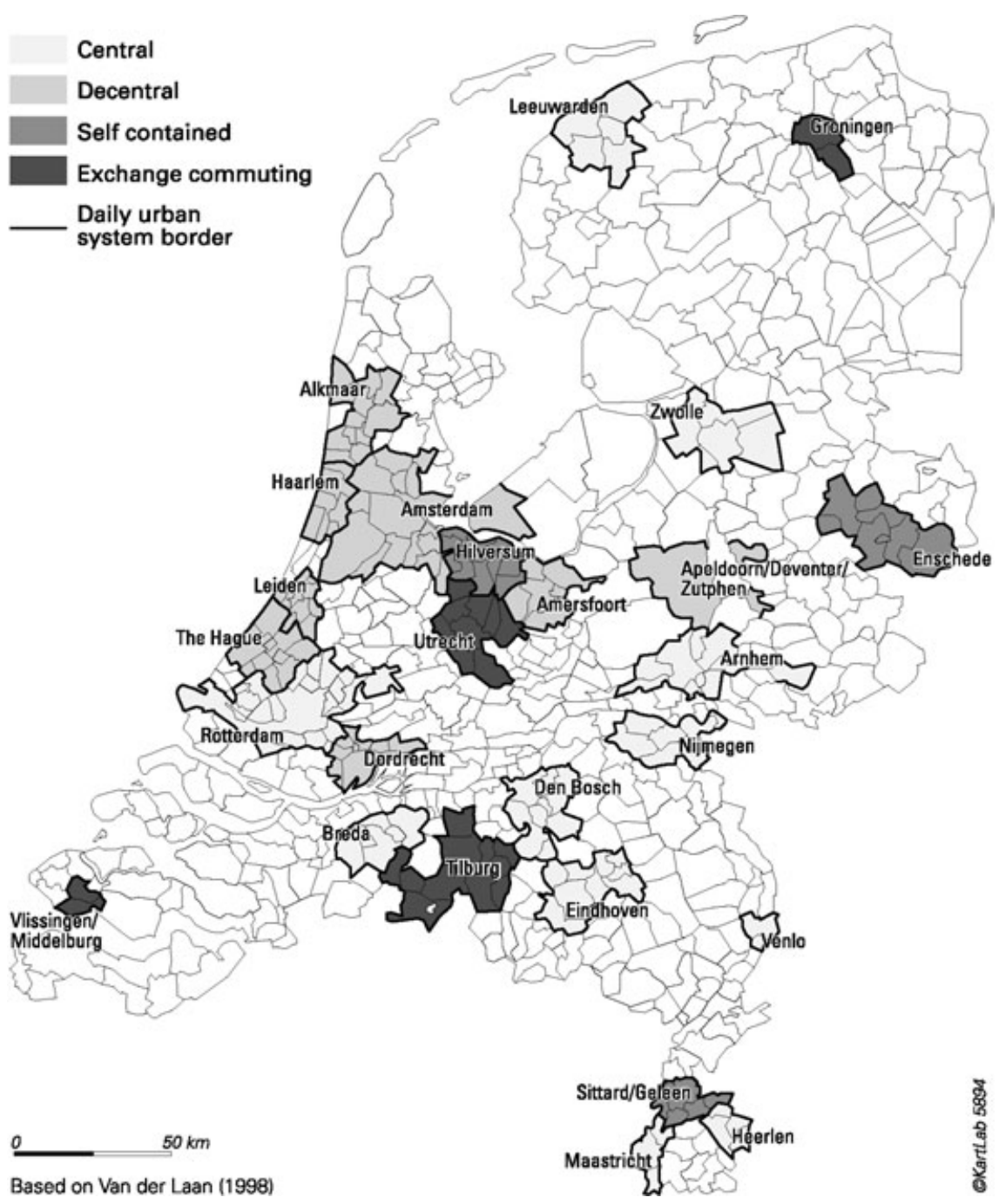

Figure 2. Spatial Distribution of DUSS OVer the Netherlands.

urbanization patterns tend to prevail outside the Randstad Holland. In contrast, in the western part of the Netherlands, employment is concentrated in logistics, entertainment, and service-related sectors, and urban regions have evolved into metropolitan areas with complex interaction patterns between lower-level spatial units.

Multilevel Regression Analysis. A regression model consists of a fixed part and a random part. The fixed part represents the systematic relationship between the dependent variable and the explanatory factors; this part encompasses the intercept and the regres- 
sion or slope coefficients. The random part allows for variation around this fixed part (Bullen, Jones, and Duncan 1998). Ordinary Least Squares (OLS) regression models are based on the assumption that the random variation around the fixed parameters is constant and does not depend on the explanatory variables - the homoscedasticity assumption. Because all observations are assumed to be mutually independent, residual variance can be summarized by a single random term. In this paper, however, it has been assumed that commute behavior depends on the characteristics of workers within the household, within residential zones, within metropolitan regions. This nested conceptualization clearly contravenes the assumptions of the independence of the observations and homoscedasticity; the application of OLS regression may, therefore, yield biased results. Multilevel regression modeling was proposed to handle the clustering or nesting of data through extension of the random part of the regression equation (Goldstein 1995; Snijders and Bosker 1999). The basic four-level model can be written as:

$$
\mathrm{Y}_{i j k l}=\beta_{0 i j k l}+\beta_{1} \mathrm{X}_{i j k l}+\mathrm{e}_{0 i j k l}
$$

where $\mathrm{Y}_{i j k l}$ is a continuous dependent variable - commute time, for instance — reported by person $i$ (level 1), in household $j$ (level 2), residing in municipality $k$ (level 3), located in DUS $l$ (level 4). The variable $\mathrm{X}_{i j k l}$ is an explanatory variable at the individual worker level and $\beta_{1}$ is the estimated regression coefficient for $\mathrm{X}_{i j k l}$. The random term $e_{i j k l}$ is the usual error term capturing the random variation among individuals, with $\mathrm{E}\left(e_{0 i j k l}\right)=0$ and $\operatorname{var}\left(e_{0 i j k l}\right)$ $=\sigma_{e 0}^{2}$. The term $\beta_{0 i j k l}$ has a fixed mean, $\gamma_{0}$, the intercept; the variation around this mean among households is captured by the random variable $u_{0 j k l}$ with $\mathrm{E}\left(u_{0 j k l}\right)=0$ and $\operatorname{var}\left(u_{0 j k l}\right)$ $=\sigma_{u 0}^{2}$. Similarly, the variation around the fixed intercept among residential municipalities is reflected by the random variable $v_{0 k l}$ and the variation among DUSs by $f_{0 l}$, which are also assumed to be normally distributed with a mean of zero and can be summarized by their variances. Thus, $\beta_{0 i j k l}$ can be written as:

$$
\beta_{0 i j k l}=\gamma_{0}+u_{0 j k l}+v_{0 k l}+f_{0 l}
$$

When the multilevel model only accommodates random variation around the intercept, it is called an intercept-only model. However, random variation may also be allowed around the other elements of the fixed part of the regression equation-the coefficient(s) for explanatory variables. In such random-slope models, the estimated regression coefficient $\beta_{1}$ is turned into a set of random variables:

$$
\beta_{1 i j k l}=\gamma_{1}+e_{1 i j k l}+u_{1 j k l}+v_{1 k l}+f_{1 l}
$$

The terms have the same meaning as before: $\gamma_{1}$ is the fixed mean slope coefficient; $u_{1 j k l}$, $v_{1 k l}$ and $f_{1 l}$ capture the random variation around this mean among household, residential municipalities, and DUSs, respectively. Again, all random terms are assumed to be normally distributed, with a mean of zero, and can be summarized by their variances. In addition, they may be correlated with other random variables at the same level of analysis, but 
they are assumed to be independent of terms at other levels. The correlation between random terms at the same level of analysis - $u_{0 j k l}$ and $u_{1 j k l}$ for example - is captured by a covariance term: $\operatorname{cov}\left(u_{0 j k l}, u_{1 j k l}\right)=\sigma_{\mathrm{u} 01}$. In (3), an additional random term $e_{1 j k l}$ is specified for the individual worker level. This is because the random variation between individual workers may not be constant. By specifying an additional variance term $e_{1 j k l}$, such effects could be incorporated into the models. A covariance term with the error term at level 1 , $\operatorname{cov}\left(e_{0 j k l}, e_{1 j k l}\right)=\sigma_{\mathrm{e} 01}$, indicates how the variance varies with an increase in the value of the explanatory variable: a positive covariance term implies that the variance around the mean effect of the independent variable becomes larger with an increase in the independent variable, while for a negative term the variance decreases.

Multilevel modeling has been extended to allow discrete rather than continuous dependent variables to be analyzed and multiple dependent variables to be considered simultaneously. If the dependent variable is discrete, as with mode choice, a generalized linear model is specified consisting of a set of linear predictors as in (1) and a nonlinear link function, which is typically a logit function in the case of a binary response variable. The resulting model is the multilevel equivalent of the traditional logistic regression or logit model. The main difference from multilevel models with a continuous dependent variable is that, for a number of technical reasons, all variance terms at the lowest level are constrained to one (Snijders and Bosker 1999).

A model with both commute distance and time as dependent variables, given their strong interdependence, is capable of providing additional insights. Unlike separate analyses, simultaneous estimation of (sub)models for commute distance and time permits analysis of whether or not a given predictor variable influences commute time when its effect on commute distance is taken into account and vice versa. The reason for analyzing both commute distance and time is that, although they may be strongly correlated, the former is directly associated with the environmental consequences of transportation, whereas the latter is related to the quality of life and the level of time pressure workers experience (Wener et al. 2003; Young and Morris 1981). A specific type of multilevel model has been developed to handle more than one dependent variable: multivariate multilevel (Goldstein 1995). In these models, another level of analysis is added to define the multivariate structure. The resulting model with an explanatory variable at the worker level $\mathrm{X}_{j k l m}$ can be expressed as:

$$
\begin{aligned}
\mathrm{Y}_{i j k l m}= & \beta_{01} \mathrm{Z}_{1 i j k l m}+\beta_{02} \mathrm{Z}_{2 i j k l m}+\beta_{11} \mathrm{Z}_{1 j k k l m} \mathrm{X}_{j k l m}+\beta_{12} \mathrm{Z}_{2 i j k l m} \mathrm{X}_{j k l m} \\
& +u_{1 j k l m} \mathrm{Z}_{1 i j k l m}+u_{2 j k l m} \mathrm{Z}_{2 i j k l m}
\end{aligned}
$$

with $\mathrm{Z}_{1 j \mathrm{kklm}}=1$ for commute distance, $\mathrm{Z}_{1 i j k l m}=0$ for commute time, and $\mathrm{Z}_{2 i j k l m}=1-\mathrm{Z}_{1 i j k l m}$. Note that, relative to (1), the subscripts have changed because the lowest level $i$ is now used to distinguish commute distance and commute time. For this reason, the terms $u_{1 j k l m}$ and $u_{2 j k l m}$ now indicate the between-individuals variation in commute distance and commute time respectively. As with the univariate model, the terms $\beta_{01}$ and $\beta_{02}$ can be expanded to include random variations around the intercept among households, residen- 
tial municipalities, and DUSs; the same is true for the slope coefficients $\beta_{11}$ and $\beta_{12}$ (see equations 2 and 3). All multilevel models presented in the remainder of the paper have been estimated with the MLwiN software (Rasbash et al. 2000).

\section{Mode Choice}

Polycentrism may lead to higher levels of automobile dependence, as argued in the introduction section. One of the manifestations of such higher levels would be a higher probability of choosing the auto driver mode to get to work. To examine the extent to which this is the case for the Netherlands, a multilevel analysis was conducted with the binary choice between commuting as an auto driver (1), and commuting by any other means of transportation (0). The prime motivation for concentrating only on the auto driver mode is that the existing literature suggests that an increase in the prominence of (solo) driving is one of the main effects of the rise of polycentric urban areas for travel behavior (Schwanen, Dieleman, and Dijist 2001). An additional, more technical reason is that with the introduction of more choice alternatives the model becomes a multinomial logit model for which the restrictive assumption of the independence of irrelevant alternatives (IIA) should be tested. Neither this nor the specification of logit models that do not require the IIA assumption is feasible with the MLwiN software. ${ }^{4}$ Two binary logit models are presented: an intercept-only model, and the final model containing a range of fixed explanatory variables (Table 2).

With respect to the intercept-only model, it is noted that the estimated constant is positive, indicating that the majority of the sample commutes by automobile. The random variables in the model show that the contribution of the residential-zone level to the variation in automobile use is fairly large. In contrast, the role of the metropolitan or Daily Urban System (DUS) level is much smaller; the estimated variance of the random variable for this level is strictly not significant at the 5 percent or 10 percent significance level. It was kept in the model specification, however, since the variation between DUSs is a main topic of interest in this study. The coefficient estimated for the household level turned out to be zero. The corresponding variance term was therefore omitted from the model specification. This result probably reflects the relatively small number of households with two commuters rather than one in the sample on which the model is estimated (11.2 percent of all households).

To illustrate how the probability of commuting as an auto driver varies between the twenty-six DUSs in the Netherlands, the intercept-only model was used to estimate residuals or deviations from the fixed intercept for each metropolitan region. ${ }^{5}$ Figure 3 displays these residuals in rank order for the twenty-six DUSs in the Netherlands; the bars indicate the 95 percent confidence interval for the estimates. The intercept estimated for a DUS is significantly different from the Netherlands average if the 95 percent confidence interval does not intersect with the dotted line. Figure 3 shows that the intercepts for Amsterdam and The Hague are significantly below the Dutch average; those for Groningen and Vlissingen/Middelburg also tend to be lower, indicating low levels of automobile commuting. On the other hand, the regions of Geleen/Sittard and Hilversum are the most auto dependent, followed by Heerlen and Tilburg. 
Table 2. MultileVel Logistic Regression Model for the Likelihood of Commuting as an AUto Driver.

\begin{tabular}{|c|c|c|c|c|}
\hline & \multicolumn{2}{|c|}{ Intercept-only model } & \multicolumn{2}{|c|}{ Full model } \\
\hline & coefficient & $t$-statistic & coefficient & t-statistic \\
\hline \multicolumn{5}{|l|}{ Fixed part } \\
\hline Intercept $\left(\gamma_{0}\right)$ & 0.340 & 7.44 & -0.455 & -1.25 \\
\hline Auto availability index & & & 3.212 & 46.82 \\
\hline Personal income $\left({ }^{*} 10,000\right.$ gld.) & & & 0.114 & 8.03 \\
\hline Low education & & & 0.235 & 4.37 \\
\hline Medium education & & & 0.234 & 4.85 \\
\hline LN (age (yr.)) & & & -0.296 & -3.58 \\
\hline Female & & & -0.414 & -6.17 \\
\hline Female single worker & & & 0.440 & 3.42 \\
\hline Female in two-worker family & & & 0.648 & 6.25 \\
\hline Female in one-worker family & & & 0.325 & 2.25 \\
\hline Single worker & & & -0.640 & -7.37 \\
\hline Two-worker family & & & -0.189 & -2.91 \\
\hline $\begin{array}{l}\text { Residential density } \\
\text { (municipality) }\end{array}$ & & & -0.104 & -2.53 \\
\hline Core city & & & -0.231 & -4.21 \\
\hline $\begin{array}{l}\text { Ratio of jobs to residents } \\
\text { (DUS) }\end{array}$ & & & -0.014 & -2.68 \\
\hline $\begin{array}{l}\text { Growth of the ratio of to } \\
\text { residents (DUS) }\end{array}$ & & & 0.084 & 1.65 \\
\hline Female in decentralized DUS & & & -0.297 & -3.83 \\
\hline $\begin{array}{l}\text { Female in exchange- } \\
\text { commuting DUS }\end{array}$ & & & -0.235 & -2.11 \\
\hline \multicolumn{5}{|l|}{$\begin{array}{l}\text { Random part } \\
\text { level 1-worker }\end{array}$} \\
\hline $\begin{array}{l}\text { Variance intercept }\left(\sigma_{e 01}^{2}\right) \\
\text { level 2-residential municipality }\end{array}$ & 1.000 & & 1.000 & \\
\hline $\begin{array}{l}\text { Variance intercept }\left(\sigma_{u 01}^{2}\right) \\
\text { level 3-DUS }\end{array}$ & 0.132 & 5.73 & 0.019 & 1.94 \\
\hline Variance intercept $\left(\sigma_{v 01}^{2}\right)$ & 0.021 & 1.42 & 0.006 & 1.03 \\
\hline
\end{tabular}

Worker commuting as an auto driver $=1$ (54.8\% of the sample); Worker commuting by other mode(s) $=0(45.2 \%)$.

$\mathrm{N}=14,590$ individuals. 
DUS-specific residual

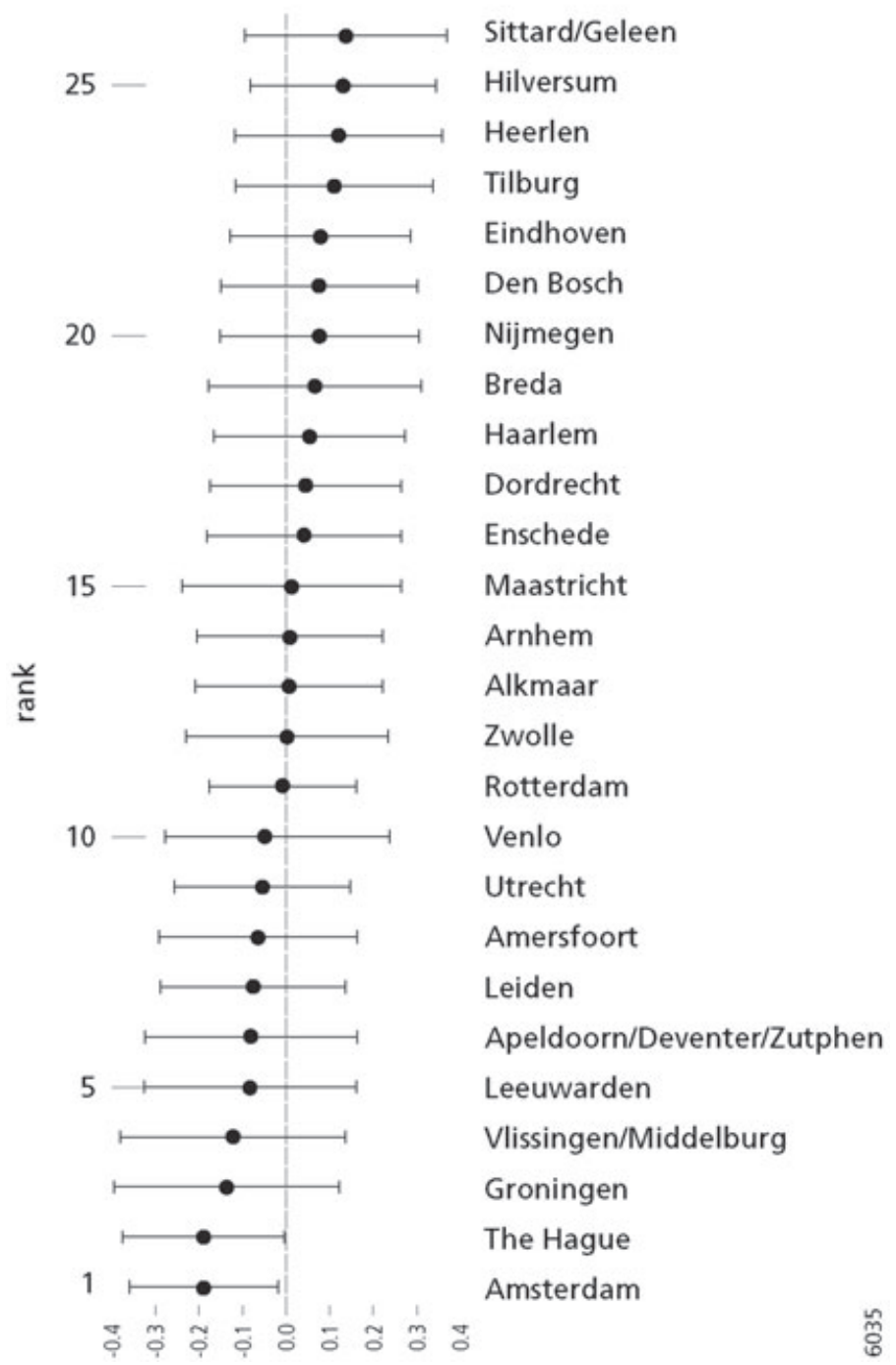

FIgURE 3. ESTIMATEd RESIDUALS FOR THE 26 DUSS IN THE INTERCEPT-ONLY MOdEL FOR MODE CHOICE. 
In order to explain these variations among metropolitan regions, a full model was estimated. Only variables with a statistically significant effect were included in the final model specification shown in Table 2. The results are consistent with the authors' hypotheses and previous studies. The probability of driving an auto to work increases as the level of auto availability and/or personal income increases. More highly educated workers are less likely to commute by automobile, which is consistent with previous findings indicating that in the Netherlands such commuters are more inclined to travel by train (Schwanen, Dieleman, and Dijist 2002). This finding may reflect the fact that many highly educated people both live and work in more urbanized areas, where commuting by train is relatively fast and convenient. In addition, the likelihood of commuting by automobile is lower for older people as well as for single workers and, to a lesser extent, people in two-worker families.

In general, women are less likely than men to drive an automobile to work. During the model-building process it became clear, however, that the effect of gender is not uniform and differs between households. Therefore several interaction variables of gender with household types were included in the model. These variables indicate that the gender difference in the probability of driving to work is much smaller in households comprising children and one worker, and that there is no difference between men and women in singleworker households. Moreover, women are more likely to commute by automobile than men in two-worker families. With a working partner and children, these women often face high levels of time pressure, since they have to combine out-of-home work activities with household maintenance tasks. Obviously, they value the efficiency and flexibility the private automobile offers.

The importance of the residential municipality level is borne out in the results of the final model. The probability of commuting as an auto driver is lower in municipalities with a higher residential density as well as in those at a short distance from the most important employment concentration situated in the core area of the DUS. Automobile use may be less attractive in high-density zones and/or at short distances from the urban core of the region because of traffic congestion and parking problems, and because the supply of public transportation is usually greater there, making transit a more attractive alternative to the automobile (Schwanen et al. 2002). The bicycle may also be a more viable choice alternative, since in high-density areas more jobs can be reached by bicycle within an acceptable commute tolerance.

At the metropolitan level, two employment indicators are related to mode choice. The ratio of jobs to residents is negatively correlated with the probability of commuting by automobile, indicating that fewer resident workers commute by auto in areas with many jobs per resident. Since more jobs are available for workers there, suitable employment may be easier to find relatively close to home. Other modes of transport, such as the bicycle, then become more attractive (Schwanen et al. 2002). This reasoning might explain, for example, the relatively low automobile use in the region of Groningen (Figure 3). Another explanation may be that employment-rich areas attract considerable inward commuting from people residing in other DUSs, or in municipalities outside the metropolitan regions. This attraction may on the one hand worsen congestion on the road network within 
the DUS, and on the other create opportunities for spatially and temporally more extensive transit networks. This explanation may apply to the regions of Amsterdam and Utrecht.

Furthermore, automobile use is greater for workers living in urban areas that experienced a substantial growth in the ratio of jobs to residents during the period 1994-1999. Three explanations may be given for this result. First, a strong growth in the number of jobs serves as an indication of economic prosperity; this empirical result may indicate that auto use tends to be greater in more prosperous regions. Second, the growth in the number of jobs during the period of economic well-being was particularly strong in the upper segments of the labor markets. The people attracted to such employment are in general more likely to commute by auto. Third, the increase in the number of jobs differed across space; growth was relatively strong on the urban fringe and in suburban areas as well as along the highways. These employment locations are strongly auto oriented and usually not well served by mass transit.

All else being equal, the influence of a monocentric or polycentric structure on mode choice is rather limited. No statistically significant effects were found for the sample as a whole. Experimentation with the model indicated, however, that for women the spatial distribution of employment vis-à-vis population does matter. This finding seems to reflect the fact that women are generally more dependent than men on the local labor market, as women's generally shorter commute distances indicate (see below). The analysis reveals that women residing in decentralized and exchange-commuting DUSs are less likely to commute as an automobile driver. This finding is consistent with the authors' expectations in the sense that the probability of commuting by automobile is relatively high in the archetypal polycentric region-the self-contained DUS. The relatively high auto use in the regions of Hilversum and Geleen-Sittard (Figure 3) would therefore seem to be mainly attributable to the spatial distribution of employment and population. In contrast, the finding that women in centralized DUSs are more likely to commute by auto than their counterparts in most polycentric regions is at odds with the authors' expectations. This paradox can, however, be explained by the fact that most decentralized regions and the largest exchange-commuting region (Utrecht) are located in the Randstad Holland (Figure 2), where the supply of public transport is of a higher standard and the road networks are more congested than elsewhere. In short, it seems that polycentrism in itself need not result in larger shares of the automobile in the mode split. A variety of factors determines the extent of auto use for commuting at the metropolitan level. Other factors seem to be more important and may overrule the anticipated effects of polycentrism on mode choice.

\section{Commute Distance and Time as an Automobile Driver}

For people driving to work, a multivariate multilevel model was estimated with two dependent variables: total daily commute distance as an auto driver, and total daily commute time as an auto driver. As indicated in section three, attention is given to both commute distance and time because the former is an indicator of the burden transportation places on the environment, while the latter is related to the level of stress commuters experience and their quality of life. To make estimated coefficients of explanatory vari- 
ables comparable across the dependent variables, the natural log of commute distance and time were taken and then standardized to follow a standard normal distribution. As with mode choice, an intercepts-only model is presented together with estimated residuals for the twenty-six DUSs, followed by a final model containing significant predictor variables relating to the individual worker, the worker's household, the residential municipality, and the DUS.

Because the dependent variables are standardized, the fixed intercepts in the interceptsonly model are very close to zero (Table 3 ). The first conclusion to be drawn from the random terms in the model is that the correlation between commute distance and commute time as an auto driver is high irrespective of the level of aggregation. The random variance and covariance terms can be used to calculate the correlation coefficients between the two dependent variables at a given level of analysis. ${ }^{6}$ At the individual worker level the correlation is 0.89 , while it is 0.87 and 0.94 respectively for the residential zone and the DUS level. Thus, commute distance and time are indeed strongly dependent on each other. That is not to say, however, that the impact of personal, household, or locational attributes is identical for the two dimensions of commute behavior.

The second main conclusion is that by far the largest part of the variation in both commute distance and commute time can be explained at the level of the individual worker. The between-municipality and between-DUS variation is very small. No more than 3 percent of the variation in either commute distance or commute time is associated with the spatial context. Nevertheless, the variation among spatial contexts, whether municipalities or DUSs, is greater for commute distance than for commute time. The dominance of the individual worker level should come as no surprise. There are many more individuals $(7,996)$ than municipalities $(210)$ or DUSs $(26)$. Furthermore, it is at the individual worker level that the most extreme values are recorded; in area-wide average indicators of commuting, the effects of individual extremes are neutralized. Nevertheless, the results clearly indicate that the variation in commute distance and time as an auto driver among workers within geographical units is much larger than the variation between residential zones and metropolitan regions.

The intercepts-only model also reveals that the share of variation to be explained at the household level differs considerably between commute distance and commute time (Table 3 ). The estimated variance term was far from statistically significant for distance. This term was therefore constrained to zero in the final intercepts-only model. In contrast, for the temporal dimension of commute behavior, the household level is quite important; it explains about 10 percent of the total variance in commute time. In other words, the commute times of the two partners in two-worker households are related to each other. This correspondence might be interpreted as indicating that decisions regarding a worker's commute time as an auto driver are not made independently of the partner's commute time, perhaps to ensure that the share of the household's time budget that is spent on auto commuting does not exceed some unobserved threshold level.

As for mode choice, the intercepts-only model was used to estimate residuals or deviations from the fixed intercept for the twenty-six metropolitan regions for both commute 
Table 3. Multilevel Regression Model of Commute Distance and Time CONTAINING ONLY FIXED INTERCEPTS.

\begin{tabular}{|c|c|c|}
\hline & coefficient & $t$-statistic \\
\hline \multicolumn{3}{|l|}{ Fixed part } \\
\hline Intercept distance $\left(\gamma_{01}\right)$ & -0.017 & 0.58 \\
\hline Intercept time $\left(\gamma_{02}\right)$ & -0.019 & 0.80 \\
\hline \multicolumn{3}{|l|}{ Random part } \\
\hline \multicolumn{3}{|l|}{ Level 1-individual worker } \\
\hline variance intercept distance $\left(\sigma_{u 01}^{2}\right)$ & 0.976 & 62.61 \\
\hline variance intercept time $\left(\sigma_{u 02}^{2}\right)$ & 0.899 & 33.31 \\
\hline $\begin{array}{l}\text { covariance intercept distance \& intercept } \\
\quad \text { time }\left(\sigma_{u 0201}\right)\end{array}$ & 0.835 & 44.57 \\
\hline \multicolumn{3}{|l|}{ Level 2-household } \\
\hline variance intercept distance $\left(\sigma_{v 01}^{2}\right)$ & 0.000 & \\
\hline variance intercept time $\left(\sigma_{v 02}^{2}\right)$ & 0.091 & 3.90 \\
\hline $\begin{array}{l}\text { covariance intercept distance \& intercept } \\
\text { time }\left(\sigma_{v 0201}\right)\end{array}$ & 0.028 & 2.24 \\
\hline \multicolumn{3}{|l|}{ Level 3-residential municipality } \\
\hline variance intercept distance $\left(\sigma_{f 01}^{2}\right)$ & 0.008 & 2.14 \\
\hline variance intercept time $\left(\sigma_{f 02}^{2}\right)$ & 0.006 & 1.67 \\
\hline $\begin{array}{l}\text { covariance intercept distance \& intercept } \\
\quad \text { time }\left(\sigma_{f 0201}^{2}\right)\end{array}$ & 0.006 & 1.77 \\
\hline \multicolumn{3}{|l|}{ Level 4-DUS } \\
\hline variance intercept distance $\left(\sigma_{g 01}^{2}\right)$ & 0.016 & 2.64 \\
\hline variance intercept time $\left(\sigma_{g 02}^{2}\right)$ & 0.010 & 2.31 \\
\hline $\begin{array}{l}\text { covariance intercept distance \& intercept } \\
\quad \text { time }\left(\sigma_{g 0201}^{2}\right)\end{array}$ & 0.012 & 2.42 \\
\hline
\end{tabular}

$N=7,996$ individuals; Log likelihood $=-16,078.6$.

distance and commute time (Figure 4). A comparison of these residuals again shows that the variation among the DUSs is larger for the commute distance as an auto driver than for commute time, as the figures on the $y$-axis indicate. In addition, the number of DUSs with an intercept that differs significantly from the Netherlands average is larger for commute distance than for commute time: six compared with three. The rank orders of the twenty-six DUSs differ somewhat; only four metropolitan regions occupy exactly the same position on both commute dimensions. However, the extremes on the low and high ends are roughly the same: both commute distance and commute time are highest in the Utrecht, Amersfoort, and Amsterdam regions and considerably below average in the 


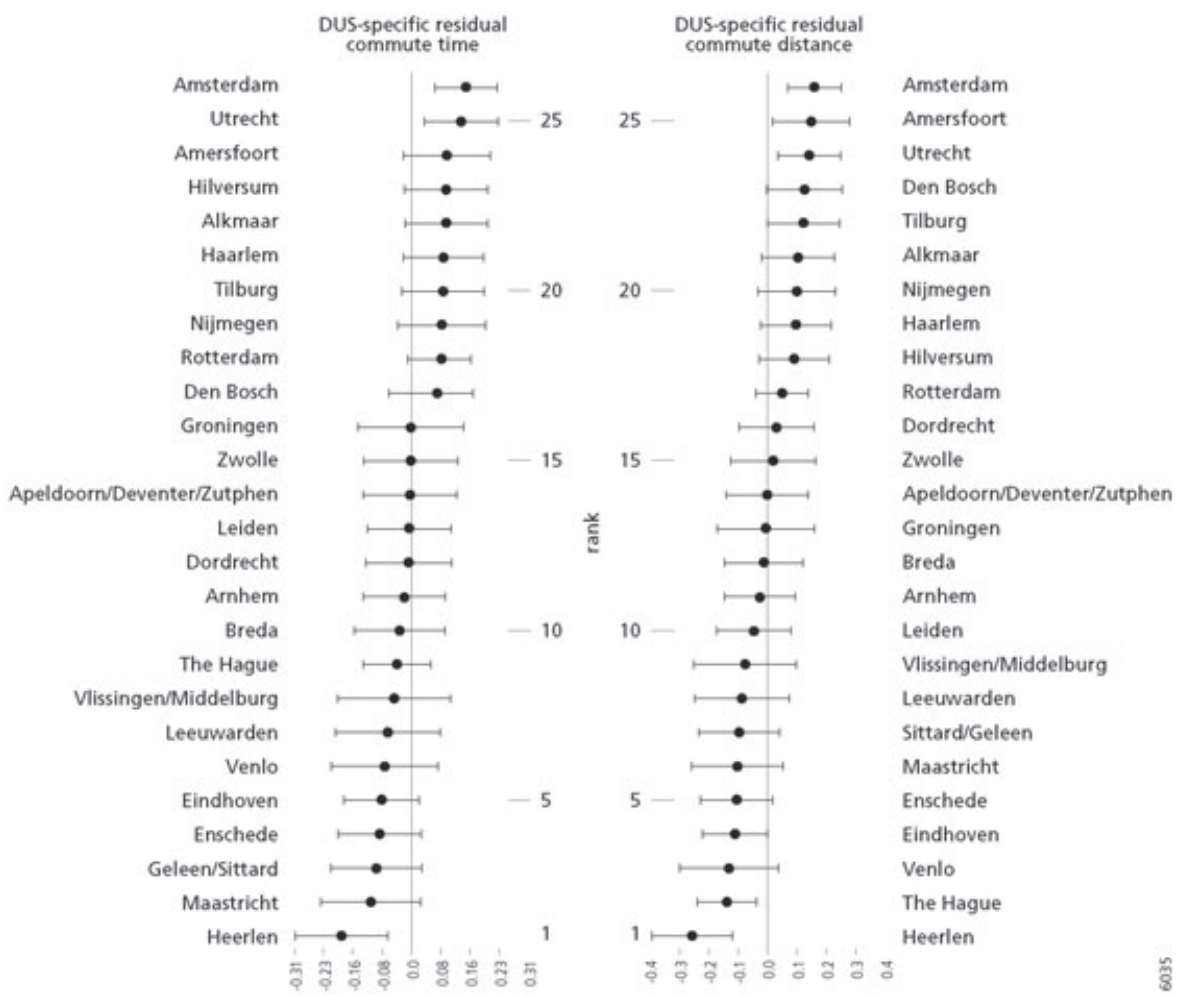

Figure 4. Estimated Residuals fOR the 26 DUSS in the INTERCEPTS-ONLY Model For Commute Distance AND TIME.

Heerlen area. The Hague is an interesting case: it occupies a mere ninth position when commute times are considered, while its commute distances are the second shortest of all the DUSs. The short distances may be attributed to the compactness of the region, squashed as it is between the North Sea coast and the Green Heart. ${ }^{7}$ On the other hand, the combination of compactness and limited opportunities for spatial extension seems to have led to relatively high congestion levels, which decrease commute speeds. In contrast, fairly large commute distances are combined with somewhat shorter commute times in the region of Den Bosch. Since the mid-1990s, this region has undergone a period of considerable growth in the number of jobs and the ratio of jobs to workers (Louter, Van Kappenhagen, and Eding 2001). This development might have led to longer commute distances, but also to somewhat higher travel speeds, implying a smaller rise, if any, in commute times.

Turning to the full model containing statistically significant explanatory variables (Table 4), it is apparent that, with the exception of age, all personal and household attributes that influence commute distance also affect commute time; however, for most vari- 
Table 4. Multivariate Multilevel Regression Model for total Daily COMMUTE Distance AND TIME BY THE Auto DRIVER MOdE.

\begin{tabular}{|c|c|c|c|c|}
\hline \multirow[t]{2}{*}{ Fixed part } & \multicolumn{2}{|c|}{ Distance } & \multicolumn{2}{|c|}{ Time } \\
\hline & coefficient & $t$-statistic & coefficient & $t$-statistic \\
\hline Intercept $\left(\gamma_{0}\right)$ & -0.026 & 0.35 & 0.163 & 4.30 \\
\hline Availability index & 0.227 & 6.29 & 0.163 & 4.30 \\
\hline $\begin{array}{l}\text { Annual year income } \\
\quad\left({ }^{*} 10,000 \text { gld. }\right)\end{array}$ & 0.060 & 8.16 & 0.049 & 6.48 \\
\hline Low education & -0.133 & -4.54 & -0.114 & 3.78 \\
\hline Medium education & -0.110 & -4.77 & -0.113 & 4.20 \\
\hline Age (*10yr.) & -0.062 & 10.58 & & \\
\hline Female & -0.362 & 10.43 & -0.264 & 7.38 \\
\hline Single worker & -0.071 & 1.99 & -0.102 & 2.73 \\
\hline Single worker with children & -0.405 & 3.10 & -0.421 & 3.09 \\
\hline Female in two-worker couple & 0.111 & 2.40 & 0.085 & 1.80 \\
\hline Female in two-worker family & -0.214 & 4.18 & -0.240 & 4.54 \\
\hline Female in one-worker family & -0.150 & 1.56 & -0.171 & 1.79 \\
\hline Growth center & 0.117 & 2.92 & 0.109 & 2.85 \\
\hline Decentralized DUS & 0.114 & 3.58 & 0.079 & 3.24 \\
\hline Exchange-commuting DUS & 0.159 & 3.52 & 0.138 & 3.82 \\
\hline Job density (DUS) & -0.021 & 3.62 & & \\
\hline Area DUS (*1,000 km²) & & & 0.607 & 3.82 \\
\hline $\begin{array}{l}\text { Growth of ratio of jobs to } \\
\text { residents (DUS) }\end{array}$ & 0.031 & 1.89 & & \\
\hline
\end{tabular}

Random part

coefficient

t-statistic

Level 1-worker

Var. intercept distance $\left(\sigma_{u 01}^{2}\right)$

1.051

13.69

Var. intercept time $\left(\sigma_{u 02}^{2}\right)$

0.973

11.82

Cov. intercept dist. \& intercept time $\left(\sigma_{u 0201}\right)$

0.883

11.91

Var. auto availability dist. $\left(\sigma_{u 11}^{2}\right)$

0.227

2.87

Cov. auto availability dist. \& intercept dist. $\left(\sigma_{u 1101}\right)$

$-0.233$

$-3.13$

Cov. auto availability dist. \& intercept time $\left(\sigma_{u 1102}\right)$

$-0.389$

$-2.67$

Var. auto availability time $\left(\sigma_{u 12}^{2}\right)$

0.250

2.79

Cov. auto availability dist. \& auto availability time

0.208

2.66 $\left(\sigma_{u 1203}\right)$

Cov. auto availability time $\&$ intercept time $\left(\sigma_{u 1202}\right)$ 
TABLE 4. (CONTINUED)

\begin{tabular}{llc}
\hline Random part & coefficient & $t$-statistic \\
\hline Level 2-household & & \\
$\quad$ Var. intercept dist. $\left(\sigma_{v 01}^{2}\right)$ & 0.059 & 1.89 \\
$\quad$ Var. intercept time $\left(\sigma_{v 02}^{2}\right)$ & 0.132 & 4.03 \\
$\quad$ Cov. intercept dist. \& intercept time $\left(\sigma_{v 0201}\right)$ & 0.080 & 2.69 \\
Level 3-residential municipality & 0.002 & 2.47 \\
$\quad$ Var. intercept dist. $\left(\sigma_{f 01}^{2}\right)$ & & \\
Level 4-DUS & 0.002 & 1.86 \\
$\quad$ Var. intercept distance $\left(\sigma_{g 01}^{2}\right)$ & & \\
\hline
\end{tabular}

$\mathrm{N}=7,996$ individuals; Log likelihood $=-15,666.5$; Model improvement $\chi^{2}=824.3$.

ables the relative importance in the explanation of commute distance or commute time varies. The socioeconomic indicators of auto availability, personal income, and education are all positively associated with both commute distance and commute time. Both commute distance and commute time by automobile increase as the number of autos per driver, the monetary reward for paid employment, and the level of educational attainment rise. The impact on distance is, however, stronger. Moreover, the influence of education is nonlinear, especially for commute time. For the auto availability index, the homoscedasticity assumption is violated. This means that, for both commute distance and commute time, the magnitude of the random variation around the fixed coefficient is unequal for different levels of auto availability. The negative covariance terms with the intercepts$\sigma_{u 1101}$ and $\sigma_{u 1202}$-indicate that the random variance around the fixed regression coefficient is lower when the level of auto availability is higher. This finding probably reflects the fact that few workers have more than one automobile at their disposal; their commute distances and times tend to resemble one another relatively strongly.

As stated above, age is related only to commute distance; older people tend to commute fewer kilometers than younger workers. The general or main effects of household structure are small; all else being equal, single workers commute less than those with a partner. If singles have children, they commute much less. The impact of these variables is somewhat greater for commute time than for commute distance, suggesting that they are proxy indicators for the level of time pressure experienced by workers in these household categories.

In accordance with previous studies, the difference between men and women in commute time is smaller than for commute distance (Hanson and Johnston 1985; Turner and Niemeier 1997). Also in line with expectations and the literature on the household responsibility hypothesis (Turner and Niemeier 1997) is the finding that women in households with children commute not only much less than men, but also considerably less than other women, particularly women with a working partner but no children. Mothers are still 
primarily responsible for childcare and household maintenance in the Netherlands (Schwanen, Dieleman, and Dijist 2002), so they are often employed part-time and close to home, which offers them more spatiotemporal flexibility. Interestingly, the impact of the interaction terms of gender and living in a household with children is greater for time than for distance, suggesting that women in these households seek to economize on commute time rather than commute distance. The time saved can be allocated to non-work activities. In contrast, women in couples without children can devote more time to paid employment and may be more career-oriented. As a result, they are prepared to commute more.

At the residential zone level, only one variable is statistically significantly related to commute distance and commute time, revealing that people living in growth centers tend to commute more. It is evident that the relatively strong mismatch between labor supply and demand in these communities (Van der Laan 1998) obliges their residents to commute more extensively than workers resident elsewhere in metropolitan regions.

The factors at the DUS level that influence commute distance and commute time as an auto driver are not identical. Commute distance for driving to and from work tends to decrease as the number of jobs per hectare rises. This finding is consistent with a priori expectations: as employment density rises, in theory more jobs are located within a certain range from any residential location in a DUS, and workers are more likely to find suitable employment closer to home. The fact that employment density has no impact on commute time may confirm that density measures also act as proxy indicators for levels of congestion (Churchman 1999); shorter automobile commute distances may be offset by lower travel speeds.

Commute distance for automobile drivers is affected by the degree of change in the ratio of employment to residents. Commute distance tends to be longer in DUSs that experienced a strong growth in the number of jobs per resident during the 1994-1999 period. It takes some time for the housing market to respond to changes in the spatial distribution of jobs, so that a temporal disequilibrium arises between residential and employment locations. Furthermore, a growth in the number of jobs also serves as an indication of economic prosperity. This result may also indicate that the DUSs with high growth tend to be the more prosperous regions, where commute distances are usually longer. Interestingly, commute time is not dependent on this growth indicator; this may be related to the spatial distribution of the additional jobs. As stated above, growth was highest in the locations that are highly accessible by private automobile, for example on the urban fringe, or along highways. Thus, the bulk of new employment is located in less congested areas, and larger commute distances may be offset by higher travel speeds.

In contrast, commute time as an auto driver rises with the size (in $\mathrm{km}^{2}$ ) of a DUS, indicating that in spatially extended urban areas the distances between employment concentrations and residential locations may be large. The question remains, however: why is commute distance not directly related to urban size in the model? This effect would seem to be included in the employment density variable.

Although the impact on distance is greater, the distribution of employment relative to residences across the metropolitan region - the monocentric or polycentric character of 
the DUS - is the only dimension of metropolitan structure that influences both commute distance and time as an auto driver. Workers living in decentralized and exchangecommuting regions commute longer measured in both time and distance than residents of centralized and self-contained DUSs. The fact that commute distance and time are lower for people in self-contained areas than for workers in other DUSs is consistent with the authors' expectations. The spatial constellation of this type of region resembles the archetypal polycentric region consisting of relatively independent, self-contained, and substitutable nodes of development.

The variables relating to level 3 (municipality) and level 4 (DUS) included in the full model successfully explain the bulk of the variation between residential zones and metropolitan regions in commute distance and especially commute time as an auto driver. This can be illustrated by a comparison of the random variance terms at these levels of analysis- $\sigma_{f 01}^{2}, \sigma_{f 02}^{2}, \sigma_{g 01}^{2}$, and $\sigma_{g 02}^{2}$-in the intercepts-only model (Table 3 ) with those in the full model (Table 4). Compared with Table 3 , the terms for distance- $\sigma_{f 01}^{2}$ and $\sigma_{g 01}^{2}$-have been greatly reduced in size in Table 4 . The random variables for time $-\sigma_{f 02}^{2}$ and $\sigma_{g 02}^{2}$-are missing in Table 4; they were omitted from the final model specification, because they were far from significantly different from zero. Thus, almost all of the variation among DUSs and residential zones for commute time as an auto driver has been accounted for. In contrast, at the levels of the individual worker and the worker's household, the model performs much less well. ${ }^{8}$ Sociodemographic variables alone are not capable of explaining the variation in commute behavior among individuals and workers. Additional factors are clearly required to capture more of this variation, including employment characteristics and attitudes toward commuting. Unfortunately, such factors are not available in the NTS data.

\section{Discussion}

This paper documents the comparison of the commute behavior of workers resident in urban areas in the Netherlands, in an attempt to ascertain the extent to which metropolitan structure affects commute patterns. Unlike some previous work, this study has not been limited to the distribution of employment vis-à-vis population, that is to say the difference between monocentrism and polycentrism. This study of metropolitan structure also encompasses employment and population density, metropolitan size, the ratio of jobs to residents, and the growth of employment and the population. In addition, data has been used at multiple levels of analysis ranging from the individual worker to the metropolitan region rather than from aggregate-level statistics alone. Three dimensions of commute behavior have been considered: mode choice, total daily commute distance as an auto driver, and total commute time as an auto driver.

The analysis has revealed that for all dimensions of commute behavior the variation among individual workers within residential zones and DUSs is much larger than the variation between such geographical units. Furthermore, the differences between residential zones within DUSs are larger than the variation between DUSs for commute mode choice. The opposite is the case for commute distance and commute time as an auto driver: the contribution of the DUS level is larger than that of the residential zone level. 
As numerous other studies have discovered, this research found that socioeconomic status and gender are important explanatory factors, and that gender differences in commute behavior depend on household structure. At the residential zone level, the expected relationships have also been established. In high-density environments and core cities, the probability of driving an auto to work is lower than elsewhere in metropolitan areas, while commute distance and commute time tend to be longer for auto drivers in growth centers. The latter result points to a qualitative mismatch between labor demand and supply in these settlements. A range of variables at the metropolitan level affect individual commute behavior. The probability of driving an auto to work falls as the number of jobs per resident rises, and commute distance by auto decreases as the number of jobs per hectare rises. In addition, if the number of jobs per resident grew during the second half of the 1990s, workers are not only more likely to commute by auto but may also cover longer distances. Interestingly, at the DUS level the factors that affect commute time differ from those that affect commute distance; only the spatial extension of the DUS is relevant to the explanation of variation in this dimension of commute behavior.

All else being equal, the relative distributions of employment and population influence commute behavior. No effects have been detected for the sample as a whole for mode choice. Nevertheless, the probability of commuting as an auto driver is lower in the majority of the polycentric DUSs for working females. It hence appears that polycentrism does not result by definition in larger probabilities for driving an auto to work, especially if well-developed transit networks serve urban areas. This conclusion may sound encouraging for those policymakers who prefer to cope with decentralization by stimulating transitoriented developments. However, the extent to which the circumstances in the Netherlands can be replicated elsewhere is unclear. It should be kept in mind that population densities have always been high and transit networks well developed in the Netherlands, particularly in the Randstad Holland.

Regarding commute distance and commute time for automobile drivers, evidence of considerable variation between the types of metropolitan region distinguished was found. In the majority of polycentric regions, commute distances and commute times as an auto driver are significantly longer than in the monocentric-oriented, centralized DUSs. Only in one specific type of polycentric region - the self-contained region consisting of relatively independent nodes of development - are auto drivers' commute distances and times equivalent to those of their counterparts in the monocentric DUSs. By and large, polycentrism has not resulted in shorter commute distances and times for auto drivers in the Netherlands.

This conclusion is at odds with a number of U.S. empirical studies arguing that polycentrism results in more efficient travel patterns. At least three factors may explain this difference (Schwanen, Dieleman, and Dijist 2003). First, within the Randstad Holland the majority of the polycentric regions are located in close proximity to each other (Figure 2). As a consequence, the number of commuters that work and live in different DUSs is larger in polycentric than in monocentric regions. This proximity clearly influences the results. Second, the role of spatial policy deserves mention. The strict regulation of the housing 
and land markets may well have hampered the co-location of residences and jobs in close proximity, creating imbalances in the locations of housing and employment. In addition to the direct impact of spatial planning through the imposition of greenbelts and other restrictions on building, there is also an indirect impact through the shortage of land and housing. These goods have become scarce, so that their prices have increased and buying a residence close to work has become virtually impossible for many households. Third, while constraints on spatial choice processes may be more severe in the Netherlands than in the U.S., commuters' preferences might also vary between these countries. The Dutch may well be less inclined to move house in response to employment changes than their American counterparts.

In short, the analysis has revealed that the distributions of employment and population across the metropolitan region are not the only factors at the DUS level capable of accounting for commute behavior. Other differences between metropolitan regions are also important for commute distance, time, and mode choice. Although the contribution of the residential zone and DUS level to the total variation in commute behavior is small, it was possible to explain the bulk of it with a fairly limited set of spatial variables. Nonetheless, the largest part of the variation at the individual worker level remains unexplained. It is clear that, apart from gender differences and the sociodemographic characteristics frequently shown to influence commute behavior, additional personal and household attributes are needed to explain the variation in behavior at this level of analysis. These additional variables will probably relate to job characteristics, housing tenure, and attitudes toward and the perceived benefits and disadvantages of commuting by private automobile.

\section{NOTES}

1. In the case of distance, the relationship is less straightforward. If travel speeds have risen because of less congestion or a change in commute mode choice, commute distance may have become larger even when commute time has decreased.

2. The terms excess commuting or wasteful commuting have been used to denote the difference between the average observed commute for a metropolitan area and the average required commute that would result from travel-minimizing behavior, given the spatial distribution of residential and employment locations (Scott, Kanaroglou, and Anderson 1997). Estimates of the amount of excess commuting vary widely depending on the method used and the characteristics of the metropolitan region considered (Buliung and Kanaroglou 2002).

3. While the number of automobiles available to a household may in some instances be enlarged because a worker accepts a job at a location that is difficult to reach by transit or bicycle (which makes auto availability an endogenous variable), it is considered here to be an important determinant of commute behavior in order to rule out the effect that the role of spatial context tends to be larger for travelers who do not have access to an automobile (Ettema, Schwanen, and Timmermans 2004).

4. The independence of irrelevant alternatives (IIA) property, which is characteristic for multinomial logit models, implies that improvements in the attractiveness of one choice alternative lead to proportionally identical decreases in the disaggregate choice probabilities of all other alternatives (Ben-Akiva and Lerman 1985). 
5. See Rasbash et al. (2000) and appendix 2.2 in Goldstein (1995) for details.

6. For a given level of analysis, the estimated covariance term is divided by the square root of the product of the variance terms, e.g., $\sigma_{u 0201} / \sqrt{ }\left(\sigma_{u 01}^{2} * \sigma_{u 02}^{2}\right)$.

7. The Green Heart is the core area of the Randstad Holland. Since World War II, government policy has included the severe restriction of the number of residences and other urban functions that could be developed there to help preserve the area as an open space (Dieleman, Dijist, and Spit 1999).

8. Compared with the intercepts-only model in Table 3, the variance terms for commute distance and commute time at the individual worker and the household levels have increased in size. This results, however, from the inclusion of the variance terms for auto availability. In a model with all random terms involving auto availability constrained to zero, the variance and covariance terms for commute distance and time at the worker and household levels are smaller than in the interceptsonly model. Nevertheless, they are still large; the proportional reduction resulting from the inclusion of the independent sociodemographic variables is limited.

\section{REFERENCES}

Anas, A., R. Arnott, and K.A. Small. 1998. Urban spatial structure. Journal of Economic Literature 26: $1426-1464$.

Atzema, O. 2001. Location and the locational networks of ICT firms in the Netherlands. Tijdschrift voor Economische and Sociale Geografie 92: 369-378.

Ben-Akiva, M.E., and L.R. Lerman. 1985. Discrete Choice Analysis: Theory and Application to Travel Demand. Cambridge, MA: The MIT Press.

Bhat, C.R. 2000. A multi-level cross-classified model for discrete response variables. Transportation Research B 34: 567-582.

Bolotte, L. 1991. Transport in France and the Ile de France. Built Environment 17: 160-171.

Buliung, R.N., and P.S. Kanaroglou. 2002. Commute minimization in the Greater Toronto Area: Applying a modified excess commute. Journal of Transport Geography 10: 177-186.

Bullen, N., K. Jones, and C. Duncan. 1997. Modelling complexity: Analysing between-individual and between place variation-A multilevel tutorial. Environment and Planning A 29: 585-609.

Cervero, R. 1989. Jobs-housing balance and regional mobility. Journal of the American Planning Association 55: 136-150.

Cervero, R., and K.-L. Wu. 1997. Polycentrism, commuting and residential location in the San Francisco Bay Area. Environment and Planning A 29: 865-886.

- 1998. Sub-centering and commuting: Evidence from the San Francisco Bay Area. Urban Studies 35: 1059-1076.

Churchman, A., 1999. Disentangling the concept of density. Journal of Planning Literature 13: 389-411.

Clark, W.A.V., Y. Huang, and S. Davies Withers. 2002. Does commuting distance matter? Commuting tolerance and residential change. Regional Science and Urban Economics 32: 199-221.

Coombes, M., and S. Raybould. 2001. Commuting in England and Wales: "People" and "place" factors. In: Pitfield, D., ed. Transport Planning, Logistics and Spatial Mismatch: A Regional Science Perspective, pp. 111-134. London: Pion Limited.

Dieleman, F.M., M.J. Dijst, and T. Spit. 1999. Planning the compact city: The Randstad Holland experience. European Planning Studies 7: 605-621. 
Ettema, D., T. Schwanen, and H. Timmermans. 2004. The effect of locational factors on task allocation and time allocation in households. Paper prepared for the 83rd Annual Meeting of the Transportation Research Board, January 12-16, 2004, Washington, D.C.

Forstall, R.L., and R.P. Greene. 1997. Defining job concentration: The Los Angeles case. Urban Geography 18: 705-739.

Giuliano, G., and K.A. Small. 1993. Is the journey to work explained by urban structure? Urban Studies 30: 1485-1500.

Goldstein, H. 1995. Multilevel statistical models. London: Edward Arnold.

Gordon, P., A. Kumar, and H.W. Richardson. 1989a. The influence of metropolitan structure on commuting time. Journal of Urban Economics 26: 138-151.

1989b. Congestion, changing metropolitan structure and city size in the United States. International Regional Science Review 12: 45-56.

Gordon, P., H.W. Richardson, and M.-J. Jun. 1991. The commuting paradox: Evidence from the top twenty. Journal of the American Planning Association 57: 416-420.

Gordon, P., and H.L. Wong. 1985. The cost of urban sprawl: Some new evidence. Environment and Planning A 17: 661-666.

Hanson, S., and I. Johnston. 1985. Gender differences in work-trip length: Explanations and implications. Urban Geography 6: 193-219.

Jun, M.-J., and C.-H.C. Bae. 2000. Estimating the commuting costs of Seoul's Greenbelt. International Regional Science Review 23: 300-315.

Lambooy, J.G. 1998. Polynucleation and economic development: The Randstad. European Planning Studies 6: 457-466.

Levinson, D.M. 1998. Accessibility and the journey to work. Journal of Transport Geography 6: 11-21.

Levinson, D.M., and A. Kumar. 1994. The rational locator: Why travel times have remained stable. Journal of the American Planning Association 60: 319-332.

1997. Density and the journey to work. Growth and Change 28: 147-172.

Louter, P., P. Van Koppenhagen, and G.J. Eding. 2001. Living and Working in City Regions. Delft: TNO Inro (in Dutch).

Mokhtarian, P.L., and I. Salomon. 2001. How derived is the demand for travel? Some conceptual and measurement considerations. Transportation Research A 35: 695-719.

Newman, P., and J. Kenworthy. 2000. Sustainable urban form: The big picture. In: Williams, K., Burton, E., and Jenks, M., eds. Achieving Sustainable Urban Form, pp. 109-120. London/New York: E. \& F.N. Spon, Taylor \& Francis Group.

Rasbash, J., W. Browne, H. Goldstein, M. Yang, I. Plewis, M. Healy, G. Woodhouse, D. Draper, I. Langford, and T. Lewis. 2000. A user's guide to MLwiN, Version 2.1. London: Multilevel Models Project, Institute of Education, University of London.

Salomon, I., and P.L. Mokhtarian. 1997. Coping with congestion: Understanding the gap between policy assumptions and behavior. Transportation Research D 2: 107-123.

Schwanen, T. 2002. Urban form and commuting behaviour: A cross-European perspective. Tijdschrift voor Economische en Sociale Geografie 93: 336-343.

Schwanen, T., F.M. Dieleman, and M. Dijst. 2001. Travel behaviour in Dutch monocentric and policentric urban systems. Journal of Transport Geography 9: 173-186. 
2002. A microlevel analysis of residential context and travel time. Environment \& Planning A 34: 1487-1507.

. 2003. Car use in Netherlands daily urban systems: Does polycentrism result in lower travel times? Urban Geography 24: 410-430.

Schwanen, T., M. Dijst, and F.M. Dieleman. 2002. Travel-time ratios for visits to the workplace: The relationship between commuting time and work duration. Transportation Research A 36: 573-592.

Scott, D.M., P.S. Kanaroglou, and W.P. Anderson. 1997. Impacts of commuting efficiency on congestion and emissions: Case of the Hamilton CMA, Canada. Transportation Research D 2: 245-257.

Shen, Q. 2000. Spatial and social dimensions of commuting. Journal of the American Planning Association 66: 68-82.

Snellen, D., A. Borgers, and H. Timmermans. 2002. Urban form, road network type, and mode choice for frequently conducted activities: A multilevel analysis using quasi-experimental design data. Environment and Planning A 34: 1207-1220.

Snijders, T.A.B., and R.J. Bosker. 1999. Multilevel analysis: An introduction to basic and advanced multilevel modeling. London: Sage Publications.

Statistics Netherlands, 1999. 1998 National travel survey-Documentation for tape users. Voorburg/Heerlen: Statistics Netherlands (in Dutch).

Turner, T., and D. Niemeier. 1997. Travel to work and household responsibility: New evidence. Transportation 24: 397-419.

Van der Laan, L. 1998. Changing urban systems: An empirical analysis at two spatial levels. Regional Studies 32: 235-247.

Wang, F. 2000. Modeling commuting patterns in Chicago in a GIS environment: A job accessibility perspective. The Professional Geographer 52: 120-133.

Wener, R.E., G.W. Evans, S. Phillips, and N. Nadler. 2003. Running for the 7:45: The effects of public transit improvements on commuter stress. Transportation 30: 203-220.

Young, W., and J. Morris. 1981. Evaluation by individuals of their travel time to work. Transportation Research Record 794: 51-59. 